ARTE GRÁFICA

\section{JOÃO BAPTISTA DA COSTA AgUIAR E O EXERCÍCIO DA SÍNTESE VISUAL}

Capas de livros são como pistas, luzes que acendem em meio a um emaranhado de sinais e mensagens com os quais nos deparamos todos os dias. Como traduzir em um pequeno espaço o conteúdo de um livro, a identidade de seu autor e ainda a marca de uma editora? Esse era um dos desafios de João Baptista da Costa Aguiar, artista gráfico, morto em abril deste ano. "Ele tinha uma força criativa, uma sensibilidade para trabalhar com traços, formas e cores e criar uma marca que o distinguia de maneira exemplar", afirma o poeta e linguista Carlos Vogt, o primeiro autor a ter uma capa de livro feita pelo artista. A aproximação de João Baptista com o mundo dos livros se deu justamente pela amizade com Vogt. Foi ele que o apresentou ao editor paulista Caio Graco, então presidente da editora Brasiliense, que editava um dos livros do poeta, Geração (1985).

$\mathrm{Na}$ capa de Cantografia: o itinerário do carteiro cartográfico (Ed. Massao Ohno \& Hucitec \& INL/MEC, 1982), ele transforma a mensagem do título em um enredo de fios e imagens, como em um mapa do tesouro, que antecipa, inclusive, os títulos dos capítulos do livro. Aqui está uma das principais características do trabalho do artista: estabelecer uma simbiose entre capa e texto, dando uma solução gráfica para a

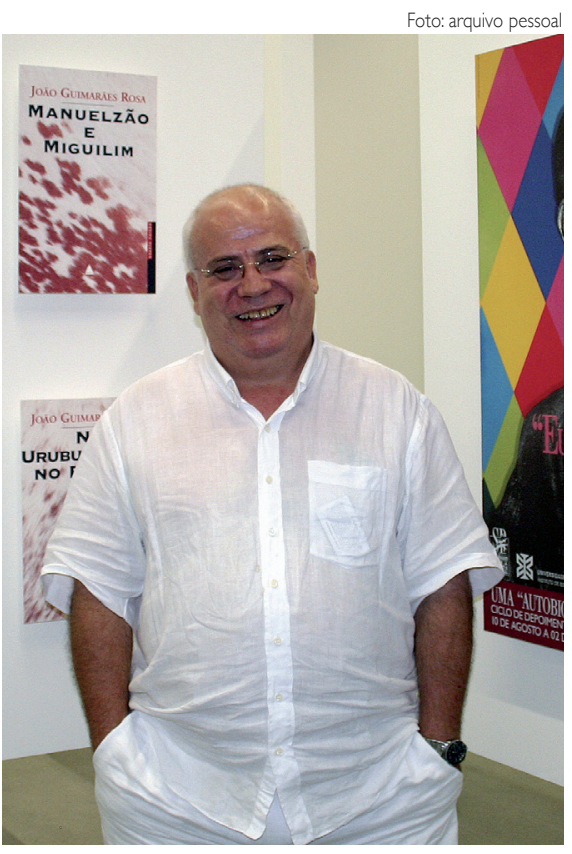

João Baptista expressava sensibilidade e grande força criativa em seus trabalhos

narrativa literária. "A capa dos livros é um dos espaços mais privilegiados, pois, enquanto o desenho de um jornal dura um dia e o de uma revista, um mês, a capa de um livro dura pelo menos dez anos na casa de uma pessoa", declarou ele, em entrevista para a Folha de S.Paulo, em 2007.

Foi assim com os trabalhos feitos para a editora Companhia das Letras, para a qual ele criou o logotipo e dezenas de capas de livros, especialmente na década de 1990. Boa parte desses trabalhos está reunido no livro João Baptista da Costa Aguiar: desenho gráfico, 1980-2006 (Senac Editores, 2006), com texto crítico da estudiosa da história do design brasileiro, Ethel Leon. Ela destaca, entre as qualidades de João Baptista, o trânsito fácil entre as escalas micro e macro, bem como a utilização de imagens inspiradas em objetos próximos, presentes em seu ambiente doméstico e cotidiano, mas sem nunca ser óbvio. "Muitos dos seus trabalhos têm uma espécie de obviedade difícil, aquela reconhecível depois de alguns segundos, depois de instantes de estranheza", escreveu Ethel.

MARCAS DE UM ARTISTA Na verdade, a ligação de Baptista com a Companhia das Letras é bem anterior ao trabalho com as capas. Ele ajudou a escolher o nome da editora e foi responsável pela criação de seu logotipo. Para Ethel, a criação de marcas e logotipos mostram o grande poder de síntese visual desse artista gráfico, onde ele demonstra capacidade de contar uma história por meio da justaposição de elementos figurativos. "Ele foi um dos primeiros a quebrar a lógica construtiva, presente nos programas de identidade corporativa desde os anos 1950", lembra a pesquisadora.

No caso da Companhia das Letras, a marca é construída com três elementos: o desenho de um meio de transporte, os fios que sustentam esse desenho e o logotipo da editora. De acordo com Ethel, trata-se de uma construção coerente com os novos tempos já que, no momento da inauguração da editora, o mundo empresarial mudava aceleradamente. Baptista captura essa transformação ao substituir uma gráfica seca, não ornamental e de imagens monolíticas pela flexibilidade e o 


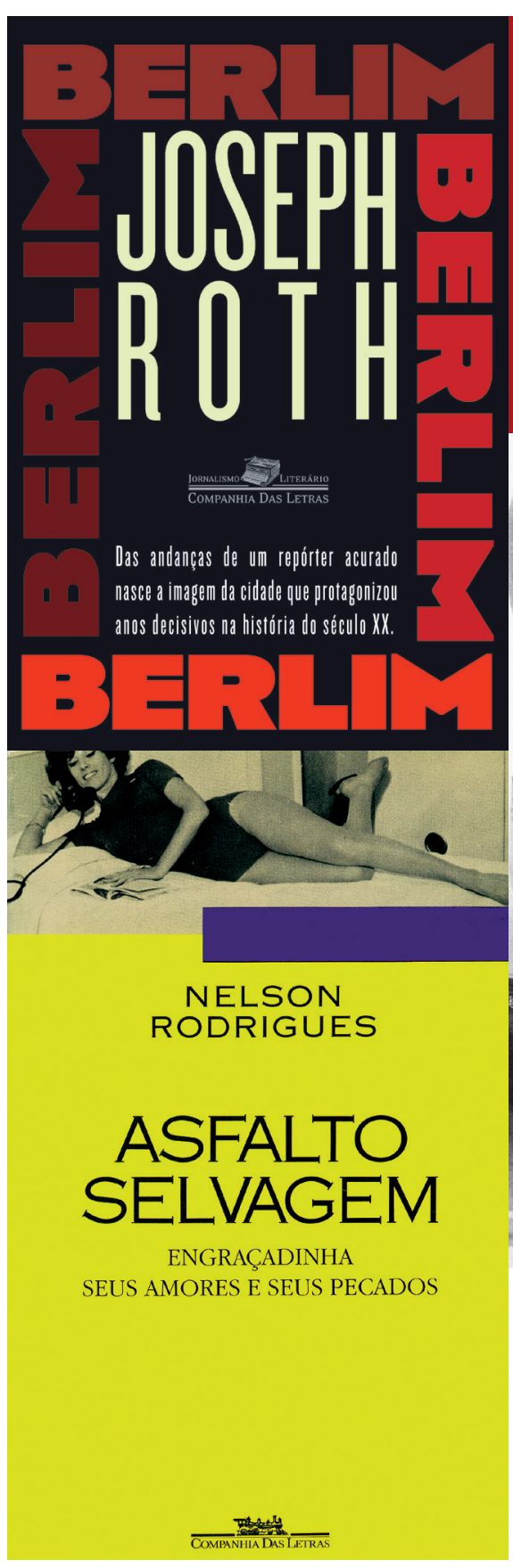

movimento. Para ele, uma empresa ou instituição tinha que ser traduzida de modo mais pessoal, daí que uma marca deveria contar uma história. "João marcou nossas vidas, de todos que fizemos a Companhia, escolhendo a sua cara, desenhando múltiplos logos premiados (...) que
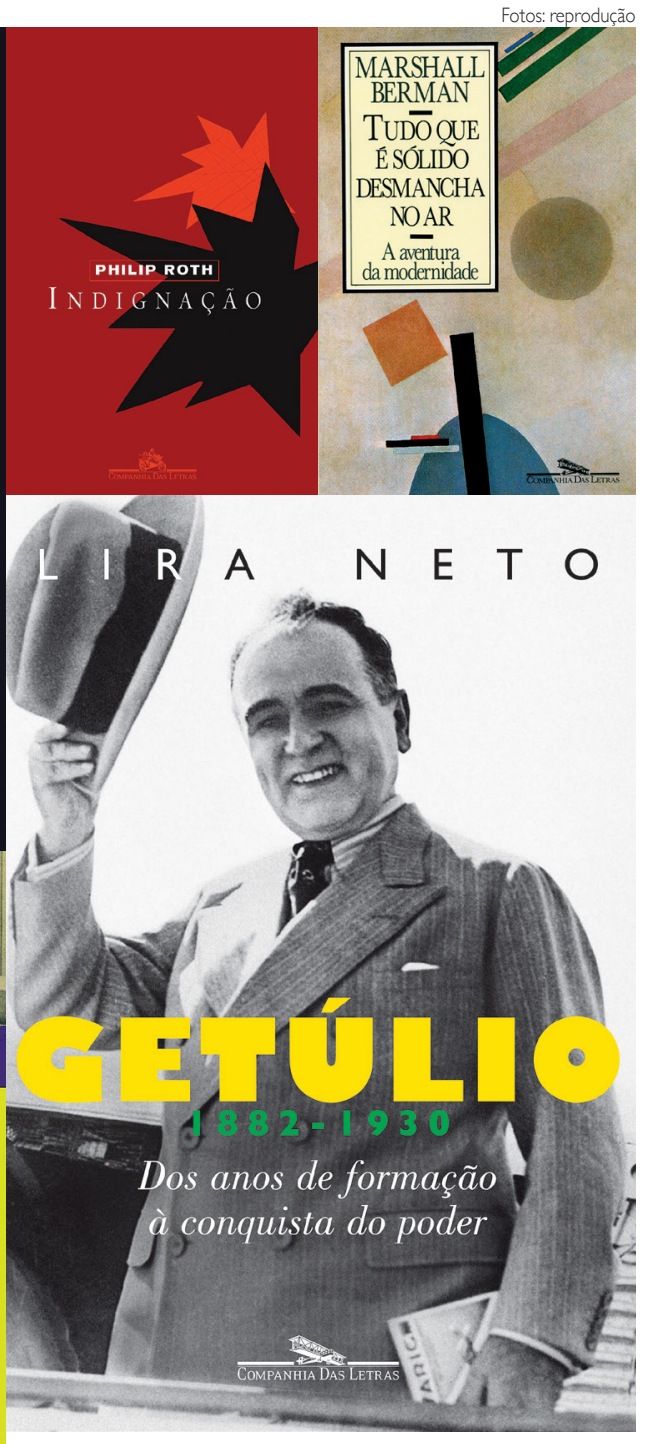

Com passagem em importantes editoras brasileiras, artista foi um dos grandes capistas da história do Brasil

ajudaram a determinar quem somos até hoje. Foi sem dúvida um dos melhores capistas da história do livro no Brasil”, escreveu Luiz Schwarcz no Blog da Companhia das Letras, um dia depois da morte do artista. Com trabalho extenso, Baptista também foi responsável por diversos projetos editoriais de revistas. Em 1970 iniciou carreira na Editora Abril e pouco tempo depois assumiu a direção de arte da revista Vogue Brasil (1976-1978).

SUAVES CAMINHOS Desde 2002, Baptista era o responsável pelo projeto gráfico da revista Ciência\&Cultura. "Quando eu apresentei o projeto de reformulação da revista para a Sociedade Brasileira para o Progresso da Ciência (SBPC), eu convidei o João Baptista para criar a identidade visual da revista, que acabou permanecendo até hoje", conta Vogt, editor chefe da publicação. Além do projeto editorial, são mais de 60 capas ao longo de 15 anos, conferindo à revista uma identidade única entre as revistas de divulgação científica no Brasil. A característica que prevalece nesse trabalho é a composição de títulos unicamente com as letras, mostrando as possibilidades expressivas das fontes. O próprio Baptista explicou essa opção como sendo inspirada nos desenhos da cartilha "Caminho suave", utilizada em sua alfabetização, e que faz aproximação visual de palavras e coisas, um procedimento similar ao efeito perseguido pelo desenho gráfico.

Paulistano, João Baptista estudou desenho e pintura na Fundação Armando Álvares Penteado (FAAP). Ao longo de seu trabalho, cultivou a tradição e a inovação, segundo Leon, estabelecendo um delicado equilíbrio entre técnicas antigas e contemporâneas, cultivando um percurso muito particular e que envolvia brincar e refletir sobre o próprio fazer do desenho. Sua morte precoce, aos 68 anos, interrompe a carreira brilhante. Brincadeiras, riscos, rabiscos e desenhos farão falta.

Patrícia Mariuzzo 